\title{
Evaluation of cell toxicity and DNA and protein binding of green synthesized silver nanoparticles
}

\author{
A.P.C. Ribeiro $^{\mathrm{a}}$, S. Anbu ${ }^{\mathrm{a}, \mathrm{b}}$, E.C.B.A. Alegriaa, ${ }^{\mathrm{a}, * *}$, A.R. Fernandes $^{\mathrm{a}, \mathrm{d}}$, P.V. Baptista ${ }^{\mathrm{d}, *}$, R. Mendes ${ }^{\mathrm{d}}$, \\ A.S. Matias ${ }^{\mathrm{d}}$, M. Mendes ${ }^{\mathrm{c}}$, M.F.C. Guedes da Silva ${ }^{\mathrm{a}}$, A.J.L. Pombeiro ${ }^{\mathrm{a}}$

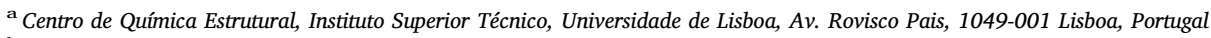 \\ ${ }^{\mathrm{b}}$ School of Chemistry, University of Birmingham, Edgbaston, B15 2TT, Birmingham, United Kingdom \\ ' Chemical Engineering Departament, Instituto Superior de Engenharia de Lisboa, Instituto Politécnico de Lisboa, 1959-007 Lisboa, Portugal \\ ${ }^{\mathrm{d}}$ UCIBIO, Departamento Ciências da Vida, Faculdade de Ciências e Tecnologia, Campus de Caparica, Universidade Nova de Lisboa, $2829-516$ Caparica, Portugal
}

\section{A R T I C L E I N F O}

\section{Keywords:}

Green chemistry

Silver nanoparticles (AgNPs)

DNA interaction

Cytotoxicity

Cancer cell lines

BSA interaction

\begin{abstract}
A B S T R A C T
Silver nanoparticles (AgNPs) were prepared by GREEN chemistry relying on the reduction of $\mathrm{AgNO}_{3}$ by phytochemicals present in black tea extract. AgNPs were fully characterized by transmission electron microscopy (TEM), ultraviolet-visible spectroscopy ((UV-vis)), X-ray diffraction (XRD) and energy dispersive absorption spectroscopy (EDS). The synthesized AgNPs induced a decrease of the cell viability in a dose-dependent manner with a low $\mathrm{IC}_{50}(0.5 \pm 0.1 \mu \mathrm{M})$ for an ovarian carcinoma cell line (A2780) compared to primary human fibroblasts $\left(\mathrm{IC}_{50} 5.0 \pm 0.1 \mu \mathrm{M}\right.$ ). The DNA binding capability of CT (calf thymus) DNA was investigated using electronic absorption and fluorescence spectroscopies, circular dichroism and viscosity titration methods. Additionally, the AgNPs strongly quench the intrinsic fluorescence of BSA, as determined by synchronous fluorescence spectra.
\end{abstract}

\section{Introduction}

Silver and gold nanoparticles (NPs) have shown their importance in catalysis [1], optics [2,3], biosensing [4] and in various biomedical applications [5]. Transition-metal NPs are often synthesized via chemical reduction by organic and inorganic reducing agents, such as hydrazine, sodium borohydride $\left(\mathrm{NaBH}_{4}\right)$ or $\mathrm{N}, \mathrm{N}$-dimethylformamide, which can also act as stabilizing agents to avoid the coalescence of NPs [6].

There has been a growing interest to eliminate the use of toxic chemicals and organic solvents as reducing agents since they show considerable deleterious effects to the environment and biological systems. Biosynthetic sustainable methods of NPs (based on top-down and bottom-up approaches), comprising either microorganism [7-9] or plant extracts [10-14], have arisen as an alternative to traditional methods and been applied to the preparation of a variety of metallic NPs [15]. Such approaches present two unequivocal advantages: i) the high diversity and abundance of plant extracts of renewable sources; and ii) the simplicity and cost-effectiveness of the methods $[15,16]$. "Green" synthesis has been focused on silver nanoparticles (AgNPs)
[17-19], whose interest is related to the easy reduction of silver(I) salts to form zerovalent silver and its antibacterial properties. Due to its health benefits and antioxidant properties, black tea [18b] has been used to produce biocompatible nanoparticles for application in health and energy. The phytochemicals present in tea, specifically phenols, flavonoids and terpenoids [20], show a dual role: i) as reducing agents to reduce silver, and ii) as stabilizers to provide a robust coating on the AgNPs in a one-pot process. Recently, microwave [21-23] and sonochemical $[24,25]$ methods have been used for the rapid generation of nanostructures [26,27].

The study of the interaction of NPs with nucleic acids is of interest to understand their possible effects on the synthesis, replication and structural integrity of DNA and RNA [28]. In fact, AgNPs derived from plant extracts have shown superior antioxidant and anticancer properties [29,30]. However, despite the extensive usage of AgNPs, very few reports [31] on the interaction of AgNPs with DNA are available, and to our knowledge, this is the first report to show that tea extract derived AgNPs act as DNA intercalator.

BSA is the most abundant protein in blood plasma and has an extensive range of physiological functions like binding, carriage of fatty

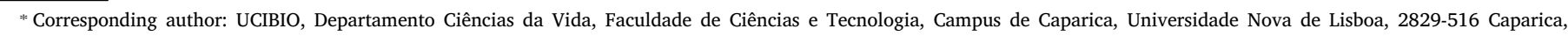
Portugal.

*** Corresponding author at: Centro de Química Estrutural, Instituto Superior Técnico, Universidade de Lisboa, Av. Rovisco Pais, 1049-001 Lisboa, Portugal.

E-mail addresses: ebastos@deq.isel.ipl.pt (E.C.B.A. Alegria), pmvb@fct.unl.pt (P.V. Baptista). 
acids, nutrients, transport, etc [32]. Thus, for downstream in vivo applications (e.g. drug delivery, receptor targeting, etc.), it is of utmost importance to study the interaction mechanism between BSA and foreign molecules. In this context, we investigated the biophysical mechanisms of AgNPs-BSA interactions using (UV-vis) and fluorescence spectroscopies.

In this work, we have prepared AgNPs via a green synthetic pathway using tea extracts. The AgNPs were fully characterized and their cytotoxicity in human ovarium carcinoma cell assessed. Interaction of AgNPs with DNA and BSA was also investigated. All these studies highlight the relevance of "green" synthetic pathways for AgNPs for a plethora of downstream applications. The simple low-cost process, relying on renewable sources, may pave the way for additional usages, some of which relying on the properties herein reported.

\section{Materials and methods}

\subsection{Materials}

All reagents and solvents were obtained from commercial sources and used as received, i.e., without further purification or drying. Black tea from Tetley, England, and $\mathrm{AgNO}_{3}$ (BDH), Sulfuric acid (97\%, Aldrich), ferric chloride (Aldrich), were used as received. All synthetic work was performed in air.

\subsection{Ag nanoparticles synthesis using black tea extracts}

AgNPs synthesis using black tea extracts was carried out as previously described [33]. A $1 \%$ tea extract solution was prepared by vigorous mixing of black tea leaves in distilled water for $15 \mathrm{~min}$ at room temperature. After filtration, $0.1 \mathrm{~mL}$ of an $\mathrm{AgNO}_{3}$ solution $(0.1 \mathrm{M})$ was added to $6 \mathrm{~mL}$ of the prepared tea extract solution, with stirring for $3 \mathrm{~h}$ at room temperature. The solution changed from pale yellow to brownish color, indicating the formation of AgNPs. UV/Vis spectroscopy was used to confirm the formation of the AgNPs due to the occurrence of the characteristic surface plasmon resonance (SPR) band at $432 \mathrm{~nm}$ of these particles.

\subsection{Test for phenolic and flavonoid compounds}

For determining the presence of polyphenols in the tea, several drops of a $5 \%$ ferric chloride aqueous solution were added to $2 \mathrm{~mL}$ of the tea extract. The appearance of a dark green color indicates the presence of polyphenolic compounds [34].

For flavonoids detection, $5 \mathrm{~mL}$ of diluted ammonium solution were mixed with $2 \mathrm{~mL}$ of tea extract and then several drops of concentrated sulfuric acid were added. The appearance of a yellowish color indicated the presence of flavonoids [34].

\subsection{Nanoparticle characterization}

The synthesized AgNPs were characterized using UV-vis spectroscopy, Scanning Electron Microscopy (SEM), Transmission Electron Microscopy (TEM) and Energy Dispersive Spectroscopy (EDS) techniques. (UV-vis)ible spectroscopic measurements of the synthesized AgNPs were carried out on a PerkinElmer Lambda 750 (UV-vis)ible spectrophotometer. TEM measurements were performed on a Transmission Electron Microscope Hitachi 8100 with ThermoNoran light elements EDS detector and digital image acquisition. Morphology and distribution of AgNPs were characterized using SEM (JEOL 7001F with Oxford light elements EDS detector and EBSD detector). The phase purity of the prepared AgNPs was determined by X-ray diffraction (XRD) performed at room temperature on a X'pert PRO of PANalytical diffractometer, $\mathrm{Cu}-\mathrm{K} \alpha \mathrm{X}$-rays of wavelength $(\lambda)=1.54056 \AA$ and data were taken for the $2 \theta$ range of $10^{\circ}$ to $90^{\circ}$ with a step of $0.02^{\circ}$.

\subsection{Stability of AgNPs in biological media}

For stability studies over time, AgNPs were incubated in phosphate buffered saline 1X (PBS) (Invitrogen), Dulbecco's Modified Eagle Medium (DMEM), DMEM without (w/o) phenol red and Roswell Park Memorial Institute (RPMI) (ThermoFisher) for $24 \mathrm{~h}$ at $37^{\circ} \mathrm{C}$, and visible spectra were recorded in $400-800 \mathrm{~nm}$ range.

\subsection{Cell culture}

Human ovarian (A2780) and colorectal (HCT116) carcinoma cell lines were grown in DMEM (Invitrogen Corp., Grand Island, NY, USA) supplemented with $10 \%$ fetal bovine serum and $1 \%$ antibiotic/antimycotic solution (Invitrogen Corp.) and maintained at $37^{\circ} \mathrm{C}$ in a humidified atmosphere of $5 \%(\mathrm{v} / \mathrm{v}) \mathrm{CO}_{2}$. Primary Dermal Normal Human Fibroblasts (Neonatal) (American Type Culture Collection (ATCC) PCS-201-010 ${ }^{\mathrm{TM}}$ ) were grown as previously described [34]. All cell lines were purchased from ATCC (www.atcc.org).

\subsection{AgNPs exposure for dose-response curves}

Cells were plated at 5000 cells/well in 96-well plates. Media was removed $24 \mathrm{~h}$ after platting and replaced with fresh media containing: 0.1-10 $\mu \mathrm{M}$ of AgNPs solution or water (vehicle control). For comparison purposes, a $1 \%$ tea extract solution was used as a control.

\subsection{Viability assays}

After $24 \mathrm{~h}$ of cell incubation in the presence or absence of the AgNPs, cell viability was evaluated with CellTiter $96^{\circ}$ AQueous NonRadioactive Cell Proliferation Assay (Promega, Madison, WI, USA), using 3-(4,5-dimethylthiazol-2-yl)-5-(3-carboxymethoxyphenyl)-2-(4sulfophenyl)-2H-tetrazolium, inner salt (MTS) as previously described $[35,36]$. In brief, this is a homogeneous, colorimetric method for determining the number of viable cells in proliferation, cytotoxicity or chemosensitivity assays. The CellTiter $96^{\circledR}$ AQueous Assay is composed of solutions of MTS and an electron coupling reagent (phenazine methosulfate, PMS). MTS is reduced by cells into a formazan product that is soluble in tissue culture medium. The absorbance of the formazan product at $490 \mathrm{~nm}$ can be measured directly from 96-well assay plates without additional processing. The conversion of MTS into the aqueous soluble formazan product is accomplished by dehydrogenase enzymes found in metabolically active cells. The quantity of formazan product was measured in a Bio-Rad microplate reader Model 680 (BioRad, Hercules, $c a$, USA) at $490 \mathrm{~nm}$, as absorbance is directly proportional to the number of viable cells in culture.

\subsection{DNA interaction experiments}

\subsubsection{Absorption spectral studies}

The DNA binding capability of the AgNPs was determined by (UV-vis) spectral titration method in $5 \mathrm{mM}$ Tris $\mathrm{HCl} / 50 \mathrm{mM} \mathrm{NaCl}$ buffer at $\mathrm{pH}$ 7.5. The concentration of CT-DNA was determined from its known extinction coefficient $\varepsilon$ value [37] $\left(6600 \mathrm{M}^{-1}\right)$ at $260 \mathrm{~nm}$. Absorption titration experiments were made using concentration of AgNPs as constant with increasing concentrations of CT-DNA. The absorbance ratio of about 1.7-1.8:1 at 260 and $280 \mathrm{~nm}$, indicating that the CT-DNA was sufficiently free of protein. The binding constant $K_{\mathrm{b}}$ was determined from the spectral titration data using the McGhee von Hippel equation [38]:

$\left.\varepsilon_{\mathrm{a}}-\varepsilon_{\mathrm{f}}\right) /\left(\varepsilon_{\mathrm{b}}-\varepsilon_{\mathrm{f}}\right)=\left(\mathrm{b}-\left(\mathrm{b}^{2}-2 K_{\mathrm{b}}^{2} \mathrm{C}_{\mathrm{t}}[\mathrm{DNA}] / s\right)^{1 / 2} / 2 K_{\mathrm{b}} \mathrm{C}_{\mathrm{t}}(\right.$

$\mathrm{b}=1+K_{\mathrm{b}} \mathrm{C}_{\mathrm{t}}+K_{\mathrm{b}}[\mathrm{DNA}] / 2 s$

where [DNA] is the concentration of CT-DNA in base pairs, $\varepsilon_{\mathrm{a}}$ is the apparent extinction coefficient of the AgNPs at a given concentration of 
CT-DNA, $\varepsilon_{\mathrm{f}}$ is the extinction coefficient of the free AgNPs, $\varepsilon_{\mathrm{b}}$ is the final extinction coefficient of the AgNPs bound to CT-DNA at the maximum extent, $K_{\mathrm{b}}$ is the equilibrium binding constant in $\mathrm{M}^{-1}, \mathrm{C}_{\mathrm{t}}$ is the total compound concentration and $\mathrm{s}$ is the fitting parameter which gives an estimate of the binding site size in base pairs. The non-linear fit analysis was done using Origin Lab version 8.1.

\subsubsection{Circular dichroism (CD) spectral studies}

Circular dichroism (CD) spectra of CT-DNA $(100 \mu \mathrm{M})$ with different concentrations of AgNPs $(0,10$ and $20 \mu \mathrm{M})$ in $5 \mathrm{mM}$ Tris $\mathrm{HCl} / 50 \mathrm{mM}$ $\mathrm{NaCl}$ buffer ( $\mathrm{pH}$ 7.5) were recorded in a Jasco-720 spectropolarimeter, using $1 \mathrm{~cm}$ path cuvette. Each spectrum was collected after averaging over at least 3 accumulations using a scan speed of $100 \mathrm{~nm}$ per min and a $1 \mathrm{~s}$ response time. The values of absorbance are measured in ellipticity, $\theta$ (mdeg), while the values of $\Delta \varepsilon$ are related to the molar ellipticity $\left(\mathrm{M}^{-1} \mathrm{~cm}^{-1}\right)$.

\subsubsection{Fluorescence spectral studies}

The ethidium bromide (EB) displacement assay by fluorescence titration method was applied to assess the relative DNA interaction properties of AgNPs to CT-DNA ( $40 \mu \mathrm{M})$ in $5 \mathrm{mM}$ Tris $\mathrm{HCl} / 50 \mathrm{mM} \mathrm{NaCl}$ buffer, $\mathrm{pH}$ 7.5. Fluorescence intensities of $\mathrm{EB}(3.3 \mu \mathrm{M})$ at $605 \mathrm{~nm}$ with an excitation wavelength of $510 \mathrm{~nm}$ were measured for different AgNPs concentrations $(0-140 \mu \mathrm{M})$. Reduction in the emission intensity was observed with the addition of the AgNPs. The apparent binding constant $\left(\mathrm{K}_{\mathrm{app}}\right)$ was obtained by using the following equation:

$\mathrm{K}_{\mathrm{app}} \times[\mathrm{AgNPs}]_{50}=\mathrm{K}_{\mathrm{EB}} \times[\mathrm{EB}]$,

where $\mathrm{K}_{\mathrm{app}}$ is the apparent binding constant of the complex studied, [AgNPs $]_{50}$ is the concentration of the AgNPs at $50 \%$ quenching of DNAbound $\mathrm{EB}$ emission intensity, $\mathrm{K}_{\mathrm{EB}}$ is the binding constant of the $\mathrm{EB}$ $\left(\mathrm{K}_{\mathrm{EB}}=1.0 \times 10^{7} \mathrm{M}^{-1}\right)$, and $[\mathrm{EB}]$ is the concentration of ethidium bromide $(3.3 \mu \mathrm{M})$ [39].

\subsubsection{Viscosity measurements}

Viscosity measurements were performed using an Ubbelodhe viscometer maintained at a constant temperature of $25.0 \pm 0.1{ }^{\circ} \mathrm{C}$ in a thermostatic bath. To minimize the complexities arising from DNA flexibility, the CT-DNA samples $(0.5 \mathrm{mM})$ were sonicated prior to viscosity measurements [40]. The flow time was measured, and each sample was tested three times to get an average calculated time. Data were presented as $\left(\eta / \eta_{0}\right)^{1 / 3}$ versus binding ratio [41], where $\eta$ is the viscosity of CT-DNA in the presence of AgNPs $(20-200 \mu \mathrm{M}), \eta_{0}$ is the viscosity of free CT-DNA.

\subsection{Protein binding studies}

Interaction of AgNPs with Bovine Serum Albumin (BSA) was studied in $5 \mathrm{mM}$ Tris $\mathrm{HCl} / 50 \mathrm{mM} \mathrm{NaCl}$ buffer, $\mathrm{pH}$ 7.5. During the titration, the BSA concentration $(1.0 \mu \mathrm{M})$ kept as constant and AgNPs concentration was varied $(0-40 \mu \mathrm{M})$ and the fluorescence spectra were recorded $(290-450 \mathrm{~nm})$ upon exciting at $280 \mathrm{~nm}$. Synchronous fluorescence spectra were recorded from 240 to $320 \mathrm{~nm}$ at $\Delta \lambda=15$ and $60 \mathrm{~nm}$, respectively, using similar concentration of the BSA and AgNPs.

\section{Results and discussion}

\subsection{Preparation of ag nanoparticles (AgNPs) using black tea extracts}

Green AgNPs were prepared by the addition of $\mathrm{AgNO}_{3}$ salt to a $1 \%$ $(\mathrm{w} / \mathrm{v})$ tea extract aqueous solution in a single-pot synthesis and stirring the mixture for $3 \mathrm{~h}$ at room temperature (see experimental section). The (UV-vis) spectrum of the $\mathrm{AgNO}_{3}$ starting aqueous solution showed a surface plasmon resonance (SPR) band centered at $305 \mathrm{~nm}$. The SPR $\lambda_{\max }$ shifts from 305 to $432 \mathrm{~nm}$ upon addition to a $1 \%$ tea extract solution, which indicates the formation of AgNPs (Fig. S1, Supporting Information). The (UV-vis) spectra of the AgNPs also exhibit a small shoulder at $c a$. $350 \mathrm{~nm}$, probably induced by high-order plasmon resonance that is also observed for AgNPs with a regular sharp corner (e.g. silver nanocubes) [42-44].

\subsection{Test for phenolic and flavonoid compounds}

The addition of several drops of a $5 \%$ ferric chloride aqueous solution to the tea extract resulted in a dark green color indicating the presence of phenolic compounds [34,45]. For flavonoids, addition of $5 \mathrm{~mL}$ of diluted ammonium solution followed by several drops of concentrated sulfuric acid resulted in a yellowish color indicating the presence of flavonoids [34,45].

\subsection{Characterization of AgNPs}

Transmission Electron Microscopy (TEM) micrograph and corresponding size distribution histogram of the synthesized AgNPs are depicted in Fig. 1 and show that AgNPs are spherically shaped with a diameter in the $30-40 \mathrm{~nm}$ range.

Fig. 2 shows the topographic SEM images of the synthesized AgNPs together with the EDS profiles exhibiting a strong signal for silver and copper (attributed to the grid used for the observations) and with very strong carbon and oxygen peaks (Fig. 2b). SEM of the AgNPs in tea extract shows the presence of dispersed flake-like structures that belong to the tea extract. EDS highlights the presence of carbon and oxygen,
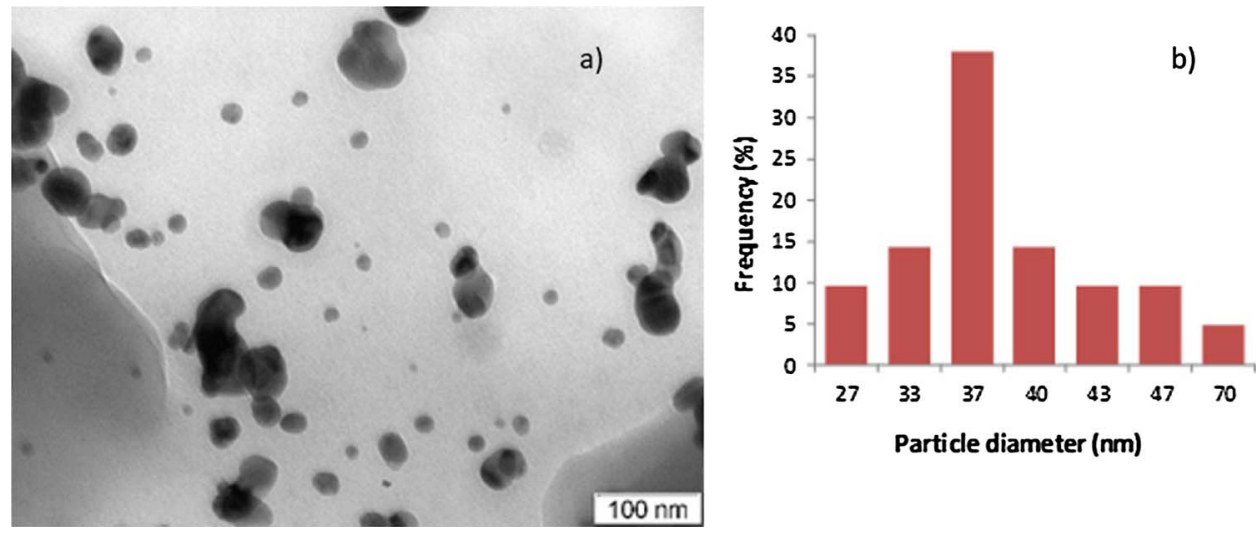

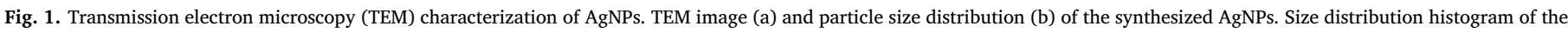
AgNPs was determined from the corresponding TEM image. 

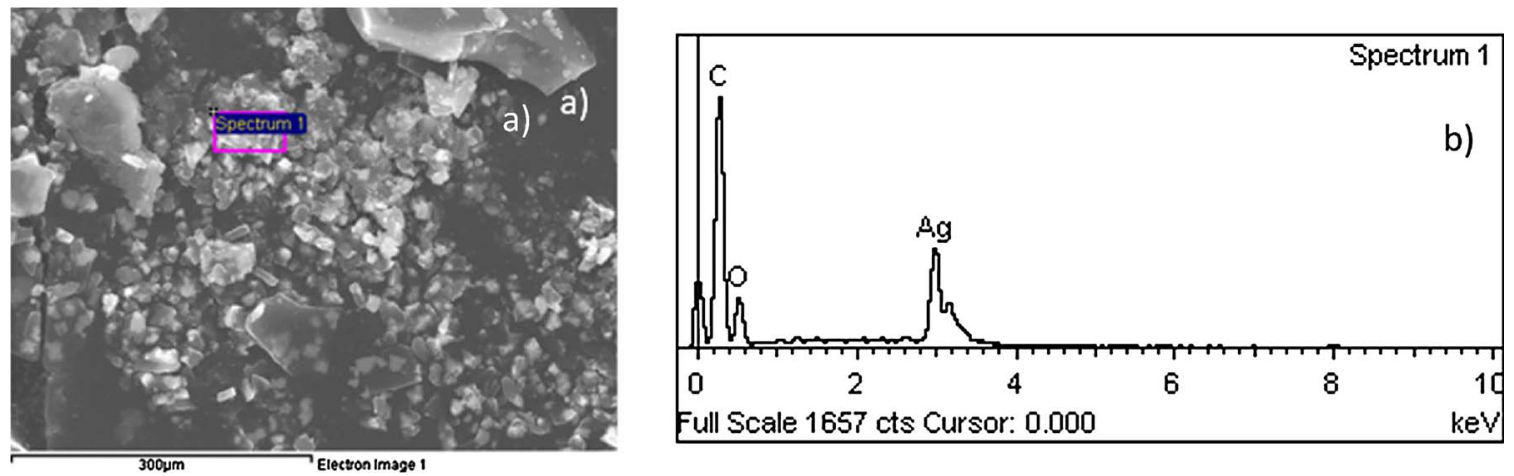

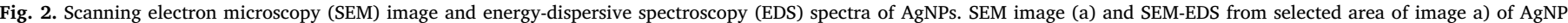
preparation. A strong peak at $3 \mathrm{keV}$ confirms the presence of Ag.

which may originate from flavonoids, phenolic or other organic biomolecules from the tea extract at the surface of AgNPs.

The XRD pattern of the sample matches that of silver (JCPDS file No. 04-0783). All peaks of the patterns for each sample can be indexed to face centered-cubic silver, where the diffraction peaks at $2 \theta$ values of $38.24,44.42,64.44,77.40^{\circ}$ can be ascribed to the reflection of (111), (200), (220), (311) crystallographic planes of the face-centered-cubic (fcc) silver crystals, respectively. The XRD pattern clearly illustrated that the main crystalline phase was silver and that no obvious other phases were found, indicating a high purity of the products - see Fig. 3. However, the Bragg peak corresponding to the $\left(\begin{array}{lll}1 & 1 & 1\end{array}\right)$ planes indicates that the NPs predominantly exposed the $\left\{\begin{array}{lll}1 & 1 & 1\end{array}\right\}$ crystal faces. The presence of $\left\{\begin{array}{lll}1 & 1 & 1\end{array}\right\}$ planes has been linked to the antibacterial activity of AgNPs [46].

\subsection{Cell toxicity assays}

Before assessing the biological effect of AgNPs in human cell lines, their stability in biological media over $24 \mathrm{~h}$ was studied by visible spectroscopy (Supporting Information Fig. S2 and Table S1). The synthesized AgNPs were stable within the concentration range required for cell viability studies.

The cytotoxic activity of AgNPs was assessed by the MTS assay on representative human cancer cell lines: ovarian cisplatin sensitive carcinoma (A2780), colorectal (HCT116) carcinoma and in normal human primary fibroblasts. A decrease of the cell viability in a dose-dependent manner was observed for both tumor cell lines after $24 \mathrm{~h}$ exposure to AgNPs (Fig. 4 and Supporting Information Fig. S3), but higher in A2780 in comparison to HCT116 (Figs. 4, Supporting Information Fig. S3 and Table 1). To assess whether the observed effect on cell viability was due to the components of the tea extract solution per se, the viability of all cell lines was also tested using $1 \%$ tea extract solution. No decrease in

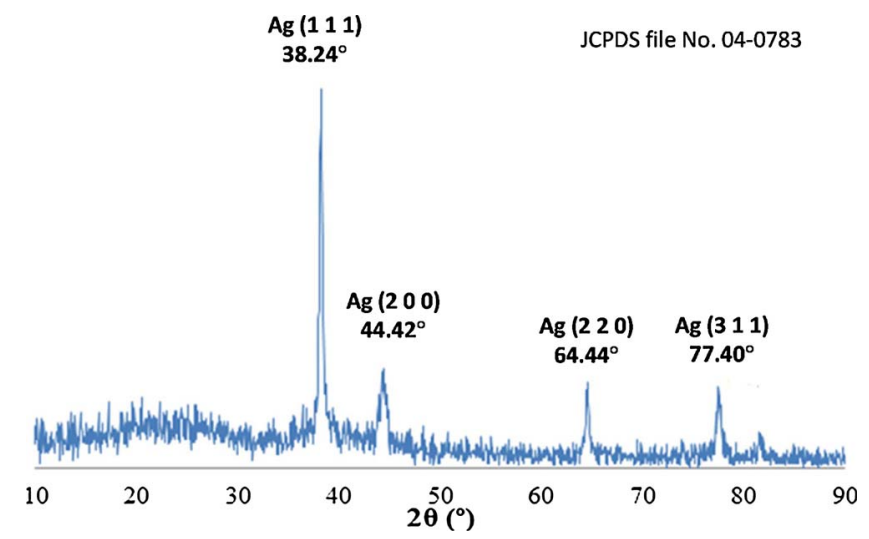

Fig. 3. XRD of AgNPs prepared by one-pot synthesis.
A2780

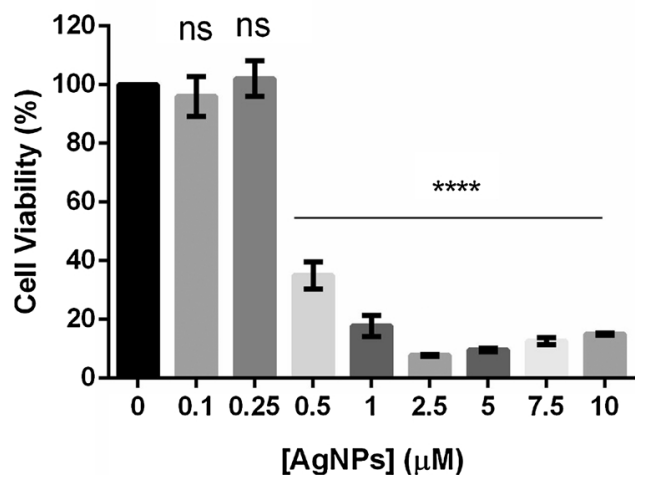

Fig. 4. Cytotoxicity of AgNPs in ovarian carcinoma (A2780) cell line. Cell viability determined by MTS assay of A2780 cell line challenged with increasing concentrations of AgNPs for $24 \mathrm{~h}$. Data normalized against control treated with $1 \%$ tea extract and expressed as mean \pm SEM of three independent assays. **** indicates statistically significant difference for $\mathrm{p}<0.01$ (as compared to control).

Table 1

$\mathrm{IC}_{50}$ values for AgNPs in human cancer cell lines (A2780, HCT116) and in normal primary human fibroblasts.

\begin{tabular}{ll}
\hline Cell line & $\mathrm{IC}_{50}(\mu \mathrm{M})$ \\
\hline A2780 & $0.5 \pm 0.1$ \\
HCT116 & $6.5 \pm 0.1$ \\
Fibroblasts & $5.0 \pm 0.1$ \\
\hline
\end{tabular}

cell viability was observed for all tested cell lines (vehicle control; $100 \%$ viability) and, as such, all data were normalized to these values.

AgNPs show higher toxicity against A2780 cell line, comparable to that of doxorubicin, a common chemotherapeutic agent (doxorubicin $\mathrm{IC}_{50}$ at $24 \mathrm{~h}$ for $\mathrm{A} 2780$ under the same experimental condition is $0.4 \pm 0.3 \mu \mathrm{M}-$ Fig. S4, Supporting Information). The tested AgNPs exhibit lower cytotoxicity against normal human primary fibroblasts, and high toxicity towards ovarian carcinoma cells ( IC $_{50}$ 10x lower) (Figs. 4 and 5 and Table 1).

\subsection{DNA binding studies}

UV-vis spectral titration is one of the main tools to determine the DNA binding capability of compounds. Those with an aromatic moiety that bind to DNA through intercalation mode usually induce hypochromism and bathochromism, which are due to a strong interaction between the aromatic chromophore and DNA nucleobases [47]. The absorption titration experiment was carried out keeping the concentration of AgNPs constant $(1.6 \mu \mathrm{M})$ 
Fibroblasts

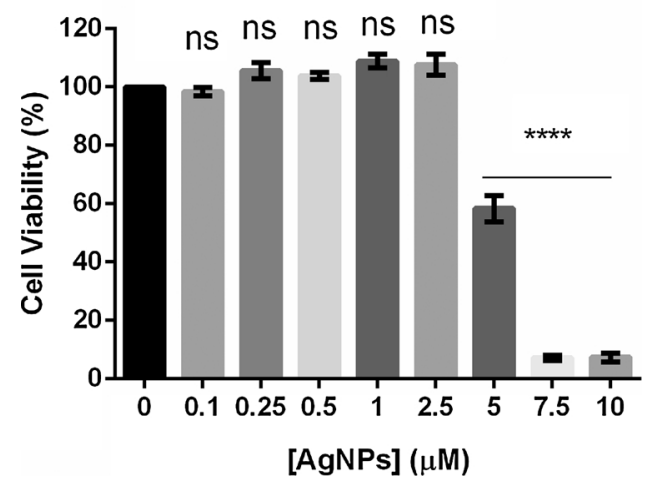

Fig. 5. Cytotoxicity of AgNPs in normal human primary fibroblasts. Cell viability determined by MTS assay of fibroblasts challenged with increasing concentrations of AgNPs for $24 \mathrm{~h}$. Data normalized against the control treated with $1 \%$ tea extract and expressed as mean \pm SEM of three independent assays. ${ }^{* * * *}$ indicates statistically significant difference for $\mathrm{p}<0.01$ (as compared to control).

to which CT-DNA was gradually added. The successive binding of AgNPs to duplex DNA led to a decrease in the absorption intensities with significant, although minor, red-shift $(\sim 3 \mathrm{~nm})$ in the UV-vis absorption spectra (Fig. 6A). The DNA binding $K_{\mathrm{b}}$ of AgNPs was calculated using the Eq. (1a), (1b) (see experimental section) and found to be $2.23( \pm 0.74) \times 10^{6} \mathrm{M}^{-1}$ $(s=0.29)$. The minor bathochromic shift of the spectral band of $\sim 3 \mathrm{~nm}$ and calculated binding site size $s(s<1)$ indicate that AgNPs preferably intercalate into the DNA [48]. The intercalating mode was corroborated by circular dichroism (CD), where the addition of AgNPs to the CT-DNA increased the intensity of both the positive and negative bands of free DNA Fig. 6B.

Fluorescence studies via the ethidium bromide (EB) displacement assay were carried out to define the intercalative binding nature of AgNPs [49,50]. Addition of AgNPs to EB-DNA solution caused an apparent reduction in emission intensities (Fig. 6C and D), indicating that the AgNPs competitively bind to CT-DNA through intercalation via their aromatic polyphenolic moieties. The Stern-Volmer quenching constant $K_{\mathrm{SV}}$ value of the AgNPs was calculated as $1.15 \times 10^{5} \mathrm{M}^{-1}$ $\left(\mathrm{R}^{2}=0.988\right)$. This also proves that the partial replacement of EB bound to DNA by AgNPs results in a decrease of the fluorescence intensity and is consistent with the above absorption and $\mathrm{CD}$ spectral results. The plot of the fluorescence intensities $\left(F / F_{0}\right)$ of $E B$ against the concentration of AgNPs yielded the apparent binding constant value for the AgNPs, $K_{\text {app }}$ of $1.43 \times 10^{6} \mathrm{M}^{-1}$. The $K_{\text {app }}$ value infers that the AgNPs interact with DNA efficiently, since the hydrophobic environment inside the DNA helix possibly reduces the accessibility of solvent water molecules to the AgNPs and their mobility is restricted at the binding site [51,52].

Addition of a typical DNA intercalator to DNA could increase the viscosity of a DNA solution due to the separation of base pairs at intercalation sites and hence an increase in overall DNA length. Upon increasing the [AgNPs]/[DNA] ratio from 0.04 to 0.20 , the relative viscosity also increases (Fig. S5, Supporting Information). The increase in relative viscosity, expected to correlate with AgNPs-DNA intercalating capability, followed the order EB > AgNPs. This suggests that the AgNPs bind with CT-DNA through intercalative mode, similarly to EB [53].

\subsection{Protein binding studies}

The quenching of fluorescence intensity in BSA is known to occur mainly by the formation of a complex between the quencher $Q$ (here AgNPs) and BSA fluorescent aminoacids, such as tryptophan residues, namely trp-134 and trp-212 [53,54]. Here we investigated the binding affinity of the AgNPs with BSA under physiological conditions and the influence of AgNPs on the BSA fluorescence intensity is shown in Fig. 7.

The strong emission intensity of BSA $(1.0 \mu \mathrm{M})$ decreased dramatically upon addition of AgNPs $(0-40 \mu \mathrm{M})$, i.e. strong quenching of fluorescence emission with a significant red-shift $(\sim 3 \mathrm{~nm})$. This might be attributed to changes in the secondary or tertiary structure of BSA, which may affect the orientation of the tryptophan residues [55]. This variation in the characteristic emission intensity of BSA suggests the existence of a strong interaction between the BSA and AgNPs. The Stern-Volmer constant $K_{\mathrm{SV}}$ of the AgNPs was determined as $2.20 \times 10^{5} \mathrm{M}^{-1}$ from the non-linear Stern-Volmer equation.
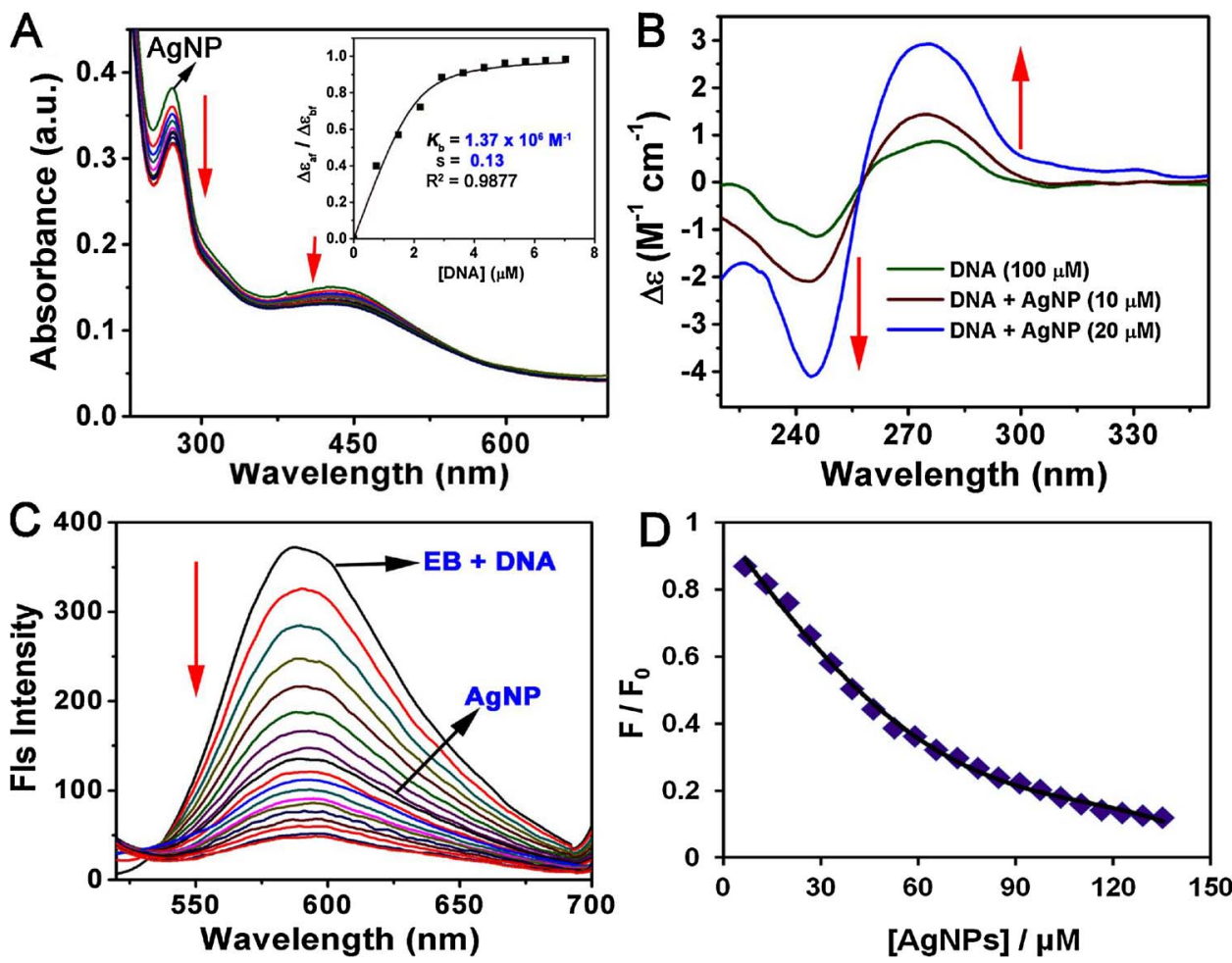

Fig. 6. DNA binding studies. (A) Electronic absorption spectra of the AgNPs $(1.6 \mu \mathrm{M})$ in the absence and presence of increasing amounts of CT-DNA $(0-75 \mu \mathrm{M})$. The arrow shows the changes on absorbance of complex upon increasing the CT-DNA concentration. Inset shows the non-linear fit of $\Delta \varepsilon_{\mathrm{af}} / \Delta \varepsilon_{\mathrm{bf}}$ versus [DNA] for AgNPs. (B) Circular dichroism spectra of CT-DNA $(100 \mu \mathrm{M})$ in the presence of increasing amounts of AgNPs (0-20 $\mu \mathrm{M})$. (C) Emission spectra of EB bound to CT DNA in $5 \mathrm{mM}$ Tris$\mathrm{HCl} / 50 \mathrm{mM} \mathrm{NaCl}$ buffer $(\mathrm{pH}=7.5)$ in the absence and presence of the AgNPs. [EB] $=3.3 \mu \mathrm{M}$, [DNA] $=40 \mu \mathrm{M}$, [AgNPs] $=0-140 \mu \mathrm{M}$. $\left(\lambda_{\mathrm{ex}}=510 \mathrm{~nm}\right)$. (D) Plot of $F / F_{0}$ vs. [AgNPs] for fluorescence quenching curve of EB-DNA by AgNPs. 

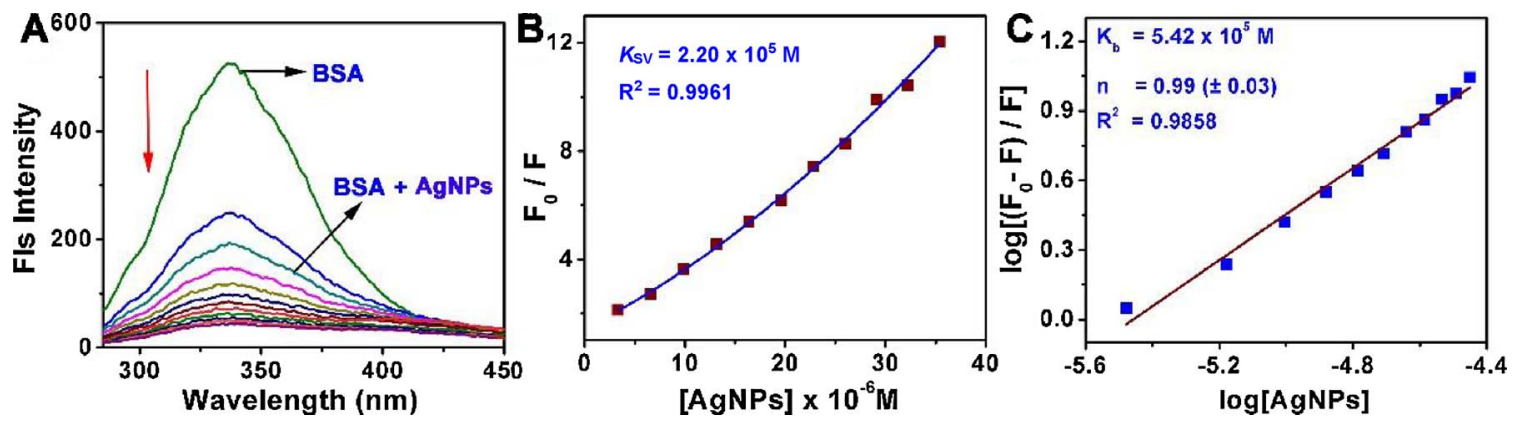

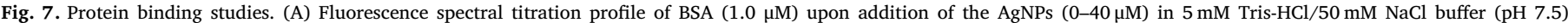
$\left(\lambda_{\text {ex }}=280 \mathrm{~nm}\right)$. (B) Non-linear Stern-Volmer plot of $F_{O} / F v s$. [Q]. (C) Scatchard plot of $\log \left[\left(F_{0}-F\right) / F\right] v s$. $\log [\mathrm{Q}]$.

$F / F_{O}=\left(1+K_{\mathrm{SV}}[\mathrm{Q}]\right)\left(1+K_{\mathrm{b}}[\mathrm{Q}]\right)$

Moreover, the Scatchard equation was used to determine the equilibrium binding constant $\left(K_{\mathrm{b}}\right)$ and number of binding sites $(n)$ existing for AgNPs as shown below:

$\log \left[\left(F_{0}-F\right) / F\right]=\log K_{\mathrm{b}}+n \log [\mathrm{Q}]$

The binding constant $\left(K_{\mathrm{b}}=5.42 \times 10^{5} \mathrm{M}^{-1}\right)$ and the number of binding sites $(n \approx 1)$ in the BSA for AgNPs were determined from the slope of the plot of $\log \left[\left(F_{0}-F\right) / F\right] v s$. $\log [Q]$. The equilibrium binding constant $\left(K_{\mathrm{b}}\right)$ and the $n$ value of approximately one suggests that the AgNPs avidly interact with BSA through a single binding site. This strong interaction was corroborated by absorption spectral analysis (see Fig. S6, Supplementary Information). Remarkably, the AgNPs triggered a significant enhancement (3.7 fold) with a small blue shift of $c a .3 \mathrm{~nm}$ of fluorescence, suggesting a predominantly static interaction between BSA and AgNPs []. Recently, our group has reported a phenolate-based $\mathrm{Cu}$ (II) complex which displayed similar fluorescent quenching profiles upon binding with BSA $\left(\mathrm{K}_{\mathrm{b}}=1.24( \pm 0.22) \times 10^{6} \mathrm{M}^{-1}\right)$ [55b]. The conformational changes in the BSA upon interaction with AgNPs were investigated by measuring the synchronous fluorescence intensity of BSA fluorophores, such as tyrosine (Tyr) $(\Delta \lambda=15 \mathrm{~nm})$ or tryptophan (Trp) $(\Delta \lambda=60 \mathrm{~nm})$ residues [57]. The spectral profiles (Fig. 8) were achieved through the simultaneous scanning of the excitation and emission monochromators while maintaining a constant wavelength interval $(\Delta \lambda=15$ or $60 \mathrm{~nm}$ ) between them [58]. Data show a decrease in fluorescence intensity at $286 \mathrm{~nm}(98 \%)$ with a remarkable red shift of $19 \mathrm{~nm}$, which indicates that the AgNPs have a very strong effect on the microenvironment of the Tyr residues. The absorbance of the BSA $\left(1 \times 10^{-6} \mathrm{M}\right)$ at excitation $(280 \mathrm{~nm})$ and emission $(343 \mathrm{~nm}$ ) wavelengths were found to be 0.013 and 0.008 , respectively, and the absorption values lower than $0.3[59,60]$. The synchronous fluorescence intensity of BSA $(\Delta \lambda=60 \mathrm{~nm})$ upon increasing AgNPs concentration dramatically decreases the intensity at $280 \mathrm{~nm}(96.7 \%)$ with a significant blue shift of $20 \mathrm{~nm}$. Together, this reveals that the conformation of BSA was strongly perturbed in such a way that the polarity around the Trp residues decreased and the hydrophobicity increased [56].

\section{Conclusions}

We have successfully synthesized stable silver nanoparticles using aqueous natural black tea extract. AgNPs formation may depend on the extracts polyphenols and flavonoids, which act as both reducing and capping agents. The synthesized AgNPs show higher cytotoxic activity against ovarian carcinoma (A2780) when compared to colorectal carcinoma cell line. The observed IC $_{50}$ in A2780 cells is 10 times lower than that for normal human primary fibroblasts and in the same range of the $\mathrm{IC}_{50}$ of doxorubicin.

The AgNPs showed a strong interaction with CT-DNA and BSA. In fact, the absorption, fluorescence and viscosity data showed that AgNPs and CT-DNA interaction occurs via an intercalative mode. Fluorescence and (UV-vis) spectroscopy studies show that AgNPs bind strongly to BSA with a single binding site. In addition, synchronous fluorescence spectroscopy shows that AgNPs have equal accessibility to the tyrosine or tryptophan residues in BSA. Together, these data provide some insights into the possible mechanisms of toxicity, where strong binding to proteins and DNA might lead to cell arrest and damage, with a concomitant decrease in cell viability.

To our knowledge, these are the first examples of water-soluble AgNPs synthesized with black tea extracts targeting DNA and proteins. Our results suggest a relevant DNA and BSA binding propensity, opening the way for potential uses in cell biology. The main advantages of the synthesized AgNPs in tea extract are related to the low cost of the process and the fact that it is a "green" approach to nanoparticle
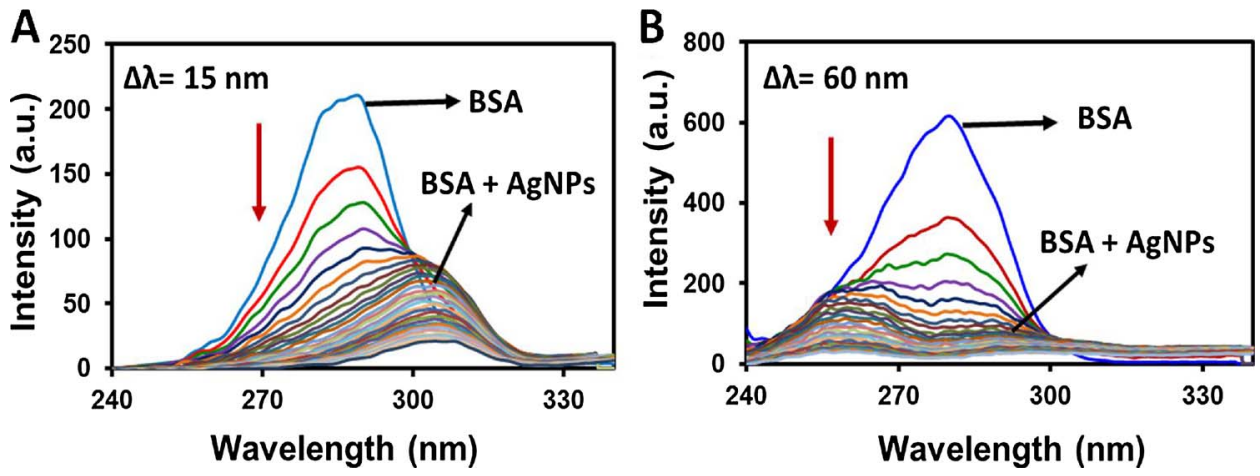

Fig. 8. Conformational changes in BSA upon interaction with AgNPs investigated by synchronous fluorescence. The inner filter effect corrected synchronous spectra of BSA ( $5 \mathrm{mM}$ Tris- $\mathrm{HCl} / 50 \mathrm{mM}$ $\mathrm{NaCl}$ buffer, $\mathrm{pH}$ 7.5) in presence of increasing concentrations of AgNPs $(0-50 \mu \mathrm{M})$, with wavelength difference of (A) $\Delta \lambda=15 \mathrm{~nm}$ and (B) AgNPs. The correction for the "Inner Filter Effect" was performed according to equation (3). 
synthesis. However, further studies are required to tune the fabrication process, namely for size and dispersion control of the formed AgNPs. The results described herein provide the foundation for further studies towards the application of silver nanoparticles in ovarian carcinoma therapy.

\section{Declarations of interest}

none.

\section{Funding}

This work has been partially supported by the Fundação para a Ciência e a Tecnologia FCT/MEC: Project UID/QUI/00100/2013 and UCIBIO (UID/Multi/04378/2013 and co-financed by the ERDF under the PT2020 Partnership Agreement (POCI-01-0145-FEDER-007728). SFRH/BPD/90883/2012 to A.P.C. Ribeiro, SFRH/BPD/76451/2011 to S. Anbu, SFRH/BD/132163/2017 to R. Mendes.

\section{Appendix A. Supplementary data}

Supplementary material related to this article can be found, in the online version, at doi:https://doi.org/10.1016/j.biopha.2018.02.069.

\section{References}

[1] M. Moreno-Mãnas, R. Pleixats, Formation of carbon - carbon bonds under catalysis by transition-metal nanoparticles, Acc. Chem. Res. 36 (2003) 638-643.

[2] B. Bo Hu, W. Shang-Bing, K. Wang, M. Zhang, Y. Shu-Hong, Microwave-assisted rapid facile "Green" synthesis of uniform silver nanoparticles: self-assembly into multilayered films and their optical properties, J. Phys. Chem. C 112 (2008) 11169-11174.

[3] A. Eychmuller, Structure and photophysics of semiconductor nanocrystals, J. Phys. Chem. B 104 (2000) 6514-6528.

[4] X. Ren, X. Meng, D. Chen, F. Tang, J. Jiao, Highly selective detection of bacterial alarmone ppGpp with an off-on fluorescent probe of copper-mediated silver nanoclusters, Biosens. Bioelectron. 21 (2005) 433-437.

[5] M. Strathmann, J. Wingender, Use of an oxonol dye in combination with confocal laser scanning microscopy to monitor damage to Staphylococcus aureus cells during colonisation of silver-coated vascular grafts, Int. J. Antimicrob. Ag. 24 (2004) 234-240.

[6] S. Iravani, H. Korbekandi, S.V. Mirmohammadi, B. Zolfaghari, Synthesis of silver nanoparticles: chemical, physical and biological methods, Res. Pharm. Sci. 9 (2014) 385-406.

[7] A.K. Jha, K. Prasad, K. Prasad, A green low-cost biosynthesis of Sb2O3 nanoparticles, Biochem. Eng. J. 43 (2009) 303-306.

[8] A.A. Bharde, R.Y. Parikh, M. Baidakova, S. Jouen, B. Hannoyer, T. Enoki, B.L.V. Prasad, Y.S. Shouche, S. Ogale, M. Sastry, Bacteria-mediated precursor-dependent biosynthesis of superparamagnetic iron oxide and iron sulfide nanoparticles, Langmuir 24 (2008) 5787-5794.

[9] A.R. Shahverdi, S. Minaeian, H.R. Shahverdi, H. Jamalifar, A. Nohi, Rapid synthesis of silver nanoparticles using culture supernatants of enterobacteria: a novel biological approach, Process. Biochem. 42 (2007) 919-923.

[10] O.V. Kharissova, H.V. Rasika Dias, B.I. Kharisov, B.O. Pérez, V.M. Jiménez Pérez The greener synthesis of nanoparticles, Trends Biotechnol. 31 (2013) 240-248.

[11] S.A.O. Santos, R.J.B. Pinto, S.M. Rocha, P.A.A.P. Marques, C.P. Neto, A.J.D. Silvestre, C.S.R. Freire, Unveiling the chemistry behind the green synthesis of metal nanoparticles, ChemSusChem 7 (2014) 2704-2711.

[12] M.N. Nadagouda, A.B. Castle, R.C. Murdock, S.M. Hussain, R.S. Varma, In vitro biocompatibility of nanoscale zerovalent iron particles (NZVI) synthesized using tea-polyphenols, Green Chem. 12 (2010) 114-122.

[13] B. Ankamwar, Biosynthesis of gold nanoparticles (green-gold) using leaf extract of Terminalia Catappa, E-J. Chem. 7 (2010) 1334-1339.

[14] J. Huang, Q. Li, D. Sun, Y. Lu, Y. Su, X. Yang, H. Wang, Y. Wang, W. Shao, N. He, J. Hong, C. Chen, Biosynthesis of silver and gold nanoparticles by novel sundried Cinnamomum camphora leaf, Nanotechnology 18 (2007) 1-11.

[15] S. Iravani, Green synthesis of metal nanoparticles using plants, Green Chem. 13 (2011) 2638-2650.

[16] A. Saravanakumar, M.M. Peng, M. Ganesh, J. Jayaprakash, M. Mohankumar, H.T. Jang, Low-cost and eco-friendly green synthesis of silver nanoparticles using Prunus japonica (rosaceae) leaf extract and their antibacterial, antioxidant properties, Artif. Cells Nanomed. Biotechnol. 45 (2017) 1-7.

[17] S. Sunkar, C. Valli Nachiyar, Biogenesis of antibacterial silver nanoparticles using the endophytic bacterium bacillus cereus isolated from Garcinia xanthochymus, Glob. J. Med. Res. 12 (2012) 953-959.

[18] (a) M. Darroudi, A.K. Zak, M.R. Muhamad, N.M. Huang, M. Hakimi, Green synthesis of colloidal silver nanoparticles by sonochemical method, Mater. Lett. 66 (2012) 117-120; (b) Q. Sun, X. Cai, J. Li, M. Zheng, Z. Chen, C.P. Yu, Green synthesis of silver nanoparticles using tea leaf extract and evaluation of their stability and antibacterial activity, Colloids Surf. A Physicochem. Eng. Asp. 444 (2014) 226-231.

[19] Y. Subba Rao, V.S. Kotakadi, T.N.V.K.V. Prasad, A. Varada Reddy, D.V.R. Sai Gopal, Molecular and biomolecular spectroscopy, Spectrochim. Acta A: Mol. Biomol. Spectrosc. 103 (2013) 156-159.

[20] C.D. Fernando, P. Soysa, Extraction kinetics of phytochemicals and antioxidant activity during black tea (Camellia sinensis L.) brewing, Nutr. J. 14 (2015) 74.

[21] M. Tsuji, M. Hashimoto, Y. Nishizawa, M. Kubokawa, Tsuji, Microwave-assisted synthesis of metallic nanostructures in solution, Chem. Eur. J. 11 (2005) 440-452.

[22] B.Bo Hu, S.-B. Wang, K. Wang, M. Zhang, S.-H. Yu, Microwave-assisted rapid facile "Green" synthesis of uniform silver nanoparticles: self-assembly into multilayered films and their optical properties, J. Phys. Chem. C 112 (2008) 11169-11174.

[23] H. Yin, T. Yamamoto, Y. Wada, S. Yanagida, Large-scale and size-controlled synthesis of silver nanoparticles under microwave irradiation, Mater. Chem. Phys. 83 (2004) 66-70.

[24] I.A. Wani, A. Ganguly, J. Ahmed, T. Ahmad, Silver nanoparticles: ultrasonic wave assisted synthesis, optical characterization and surface area studies, Mater. Lett. 65 (2011) 520-522.

[25] M. Darroudi, A.K. Zak, M.R. Muhamad, N.M. Huang, M. Hakimi, Green synthesis of colloidal silver nanoparticles by sonochemical method, Mater. Lett. 66 (2012) $117-120$.

[26] B. Baruwati, V. Polshettiwar, R.S. Varma, Glutathione promoted expeditious green synthesis of silver nanoparticles in water using microwaves, Green Chem. 11 (2009) 926-930.

[27] M. Darroudi, M.B. Ahmad, A.H. Abdullah, N.A. Ibrahim, Green synthesis and characterization of gelatin-based and sugar-reduced silver nanoparticle, Int. J. Nanomed. 6 (2011) 569-574.

[28] H. Colfen, S. Mann, Higher-Order organization by mesoscale self-assembly and transformation of hybrid nanostructures, Angew. Chem. 42 (2003) 2350-2365.

[29] U. Kreibig, M. Vollmer, Optical Properties of Metal Clusters, Springer Series in Material Science, Berlin, 1995, pp. 187-201.

[30] D. Nayak, S. Pradhan, S. Ashe, P.R. Rauta, B. Nayak, Biologically synthesised silver nanoparticles from three diverse family of plant extracts and their anticancer activity against epidermoid A431 carcinoma, J. Colloid Interface. Sci. 457 (2015) 329-338.

[31] M. Rahban, A. Divsalar, A.A. Saboury, A. Golestani, Nanotoxicity and spectroscopy studies of silver nanoparticle: calf thymus DNA and k562 as targets, J. Phys. Chem. C 114 (2010) 5798-5803.

[32] A. Bhogale, N. Patel, P. Sarpotdar, J. Mariam, P.M. Dongre, A. Miotello, D.C. Kothari, Systematic investigation on the interaction of bovine serum albumin with $\mathrm{ZnO}$ nanoparticles using fluorescence spectroscopy, Colloid Surf. B. 102 (2013) 257-264.

[33] L.M. Liz-Marzán, Tailoring surface plasmons through the morphology and assembly of metal nanoparticles, Langmuir 22 (2006) 32-41.

[34] P.J. Babu, P. Sharma, S. Saranya, R. Tamuli, U. Bora, Nanomater. Nanotechnol. 3 (2013) 2013. Art. 4.

[35] A. Silva, D. Luis, S. Santos, J. Silva, A.S. Mendo, L. Coito, T.F. Silva, M.F. da Silva, L.M. Martins, A.J. Pombeiro, P.M. Borralho, C.M. Rodrigues, M.G. Cabral, P.A. Videira, C. Monteiro, A.F. Fernandes, Biological characterization of the antiproliferative potential of co(II) and sn(IV) coordination compounds in human cancer celllines: a comparative proteomic approach, Drug Metabol. Drug Interact. 28 (2013) 167-176.

[36] O.A. Lenis-Rojas, A.R. Fernandes, C. Rodrigues, P.V. Baptista, F.M. Marques, D. Pérez-Fernández, J. Guerra, L.E. Sanchez, D. Vazquez-Garcia, M. Lopez-Torres, A. Fernández, J.J. Fernández Sánchez, Heteroleptic mononuclear compounds of ruthenium(II): synthesis, structural analyses, in vitro antitumor activity and in vivo toxicity on zebrafish embryos, Dalton Trans. 45 (2016) 19127-19140.

[37] M.E. Reichmann, S.A. Rice, C.A. Thomas, P. Doty, A further examination of the molecular weight and size of desoxypentose nucleic acid, J. Am. Chem. Soc. 76 (1954) 3047-3053.

[38] J.D. McGhee, P.H. von Hippel, Theoretical aspects of DNA-protein interactions: cooperative and non-co-operative binding of large ligands to a one-dimensional homogeneous lattice, J. Mol. Biol. 86 (1974) 469-489.

[39] K.D. Karlin, I. Cohenn, J.C. Hayes, A. Farooq, J. Zubieta, Models for methemocyanin derivatives: structural and spectroscopic comparisons of related azido-coordinated (N.) mono- and dinuclear copper(II) complexes, Inorg. Chem. 26 (1987) 147-153.

[40] J.B. Chaires, N. Dattagupta, D.M. Crothers, Studies on interaction of anthracycline antibiotics and deoxyribonucleic acid: equilibrium binding studies on interaction of daunomycin with deoxyribonucleic acid, Biochemistry 21 (1982) 3933-3940.

[41] G. Cohen, H. Eisenberg, Viscosity and sedimentation study of sonicated dna-proflavine complexes, Biopolymers 8 (1969) 45-55.

[42] N. Ahamad, A. Bottomley, A. Ianoul, Optimizing refractive index sensitivity of supported silver nanocube monolayers, J. Phys. Chem. C 116 (2012) 185-192.

[43] M.A. Mahmoud, C.E. Tabor, M.A. El-Sayed, surface-enhanced raman scattering enhancement by aggregated silver nanocube monolayers assembled by the langmuir-blodgett technique at different surface pressures, J. Phys. Chem. C 113 (2009) 5493-5501.

[44] Y. Hong Lee, H. Chen, Q.-H. Xu, J. Wang, Refractive index sensitivities of noble metal nanocrystals: the effects of multipolar plasmon resonances and the metal type, J. Phys. Chem. C 115 (2011) 7997-8004.

[45] D.F. Meo, V. Lemaur, J. Cornil, R. Lazzaroni, J.L. Duroux, Y. Olivier, P. Trouillas, Free radical scavenging by natural polyphenols: atom versus electron transfer, J. Phys. Chem. A 117 (2013) 2082-2092.

[46] N. Aziz, M. Faraz, R. Pandey, M. Shakir, T. Fatma, A. Varma, I. Barman, R. Prasad, Facile algae-derived route to biogenic silver nanoparticles: synthesis, antibacterial, 
and photocatalytic properties, Langmuir 31 (2015) 11605-11612.

[47] S. Roy, R. Sadhukhan, U. Ghosh, T.K. Das, Interaction studies between biosynthesized silver nanoparticle with calf thymus DNA and cytotoxicity of silver nanoparticles, Spectrochim. Acta A Mol. Biomol. Spectrosc. 141 (2015) 176-184.

[48] P.K. Sasmal, A.K. Patra, M. Nethaji, A.R. Chakravarty, Synthesis and in vitro antitumor activity of two mixed-ligand oxovanadium(IV) complexes of schiff base and phenanthroline, Inorg. Chem. 45 (2007) 11112-11121.

[49] A.G. Krishna, D.V. Kumar, B.N. Khan, S.K. Rawal, K.N. Ganesh, Taxol-DNA inter actions: fluorescence and CD studies of DNA groove binding properties of taxol, Biochim. Biophys. Acta 1381 (1998) 104-112.

[50] R.F. Pasternack, M. Cacca, B. Keogh, T.A. Stephenson, A.P. Williams, F.J. Gibbs, DNA-interacting and biological properties of copper(II) complexes from amidino-Omethylurea, J. Am. Chem. Soc. 113 (1991) 6835-6840.

[51] A.K. Patra, T. Bhowmick, S. Roy, S. Ramakumar, A.R. Chakravarty, Copper(II) complexes of L-arginine as netropsin mimics showing DNA cleavage activity in red light, Inorg. Chem. 48 (2009) 2932-2942.

[52] D.S. Sigma, A. Mazuder, D.M. Perrin, Chemical nucleases, Chem. Rev. 93 (1993) 2295-2316.

[53] J.R. Lakowicz, Principles of Fluorescence Spectroscopy, Plenum, New York, 2006, pp. 63-95.

[54] T. Peters, Serum albumin, Adv. Protein Chem. 37 (1985) 161-245.

[55] A. Bhogale, N. Patel, P. Sarpotdar, J. Mariam, P.M. Dongre, A. Miotello,
D.C. Kothari, Systematic investigation on the interaction of bovine serum albumin with $\mathrm{ZnO}$ nanoparticles using fluorescence spectroscopy, Colloid Surf. B: Biointerfaces 102 (2013) 257-264.

[56] (a) D.S. Raja, N.S.P. Bhuvanesh, K. Natarajan, Structure-activity relationship study of copper(II) complexes with 2-oxo-1,2-dihydroquinoline-3-carbaldehyde (4'-methylbenzoyl) hydrazone: synthesis, structures, DNA and protein interaction studies, antioxidative and cytotoxic activity, J. Biol. Inorg. Chem. 17 (2012) 223-237; (b) S. Anbu, A. Paul, A.P.C. Ribeiro, M.F.C. Guedes da Silva, M.L. Kuznetsov, A.J.L. Pombeiro, Biomolecular interaction, catecholase like activity and alkane oxidation in ionic liquids of a phenylcarbohydrazone-based monocopper(II) complex, Inorg. Chim. Acta 450 (2016) 426-436.

[57] P. Qu, H. Lu, X.Y. Ding, Y. Tao, Z. Lu, Study on the interaction of 6-thioguanine with bovine serum albumin by spectroscopic techniques, J. Mol. Struct. 920 (2009) $172-177$

[58] H. Yan, S.L. Zhao, J.G. Yang, X.D. Zhu, G.L. Dai, H.D. Liang, F.Y. Pan, L. Weng, Interaction between levamisole hydrochloride and bovine serum albumin and the influence of alcohol: spectra, J. Sol. Chem. 38 (2009) 1183-1192.

[59] E.P. Kirby, Fluorescence instrumentation and methodology, in: R.F. Steiner, L. Weinryb (Eds.), Excited States of Proteins and Nucleic Acids, Plenum Press, New York, 1971, pp. 31-56.

[60] M.E. Pacheco, L. Bruzzone, Synchronous fluorescence spectrometry: conformational investigation or inner filter effect? J. Lumin. 137 (2013) 138-142. 